\title{
Os reflexos de uma oficina na mudança das concepções de professores: um estudo no contexto dos materiais manipuláveis
}

\author{
Mylena Simões Campos \\ Jorge Henrique Gualandi
}

\begin{abstract}
Resumo: Esta pesquisa teve como objetivo descrever quais as possíveis contribuições de uma oficina para as mudanças nas concepções dos professores acerca dos Materiais Manipuláveis no ensino de Matemática. Desenvolveu-se um trabalho de abordagem qualitativa com dez professoras que ensinam Matemática na Educação Básica, em uma escola pública, situada no município de Marataízes, no sul do estado do Espírito Santo. Metodologicamente, a pesquisa foi desenvolvida mediante dois questionários, uma oficina e análise dos dados coletados à luz dos teóricos abordados. Verificou-se que três professoras possivelmente mudaram as suas concepções. Das possíveis mudanças, duas se referem à finalidade de trabalhar com os materiais e a outra diz respeito à possibilidade de utilizar esses recursos na sala de aula.
\end{abstract}

Palavras-chave: Educação Matemática. Formação continuada de professores que ensinam Matemática. Materiais Manipuláveis. Concepções.

\section{The reflections of a workshop in changing teachers' conceptions: a study in the context of manipulated materials}

Abstract: This research aimed to describe the possible contributions of a Workshop to the changes in teachers' conceptions about Manipulable Materials in the teaching of Mathematics. A qualitative approach was developed with ten teachers who teach Mathematics in Basic Education, in a public school, located in the municipality of Marataízes, in the south of the state of Espirito Santo. Methodologically, the research was developed through two questionnaires, a workshop and analysis of the data collected in the light of the theorists approached. It was found that three teachers possibly changed their conceptions. Of the possible changes, two refer to the purpose of working with the materials and the other concerns the possibility of using these resources in the classroom.
Mylena Simões Campos Licenciada em Matemática pelo Instituto Federal de Educação, Ciência e Tecnologia do Espírito Santo (IFES), campus Cachoeiro de Itapemirim. Espírito Santo, Brasil. (iD) orcid.org/0000-0002-0553-3450 $\triangle$ mylenadecampos@gmail.com

Jorge Henrique Gualandi Doutor em Educação Matemática. do Instituto Federal de Educação, Ciência e Tecnologia do Espírito Santo (IFES), campus Cachoeiro de Itapemirim. Professor do Programa de Pós-Graduação em Ensino, Educação Básica e Formação de Professores da Universidade Federal do Espírito Santo (UFES), campus Alegre. Espírito Santo, Brasil. (iD) orcid.org/0000-0002-0302-7650

\jhgualandi@gmail.com

Recebido em 29/08/2020 Aceito em 20/10/2020 Publicado em 23/11/2020

Keywords: Mathematics Education. Continuing education of teachers who teach Mathematics. Manipulable Materials. Conceptions.

\section{Las reflexiones de un taller para cambiar las concepciones de los profesores: un estudio en el contexto de materiales manipulados}

Resumen: Esta investigación tuvo como objetivo describir las posibles contribuciones de un Taller a los cambios en las concepciones de los docentes sobre los Materiales Manipulables en la enseñanza de las Matemáticas. Se realizó un trabajo de abordaje cualitativo con diez profesores 
que imparten Matemáticas en Educación Básica, en una escuela pública, ubicada en el municipio de Marataízes, en el sur del estado de Espírito Santo. Metodológicamente, la investigación se desarrolló a través de dos cuestionarios, un taller y el análisis de los datos recogidos a la luz de los teóricos abordados. Se encontró que posiblemente tres profesores cambiaron sus concepciones. De los posibles cambios, dos se refieren al propósito de trabajar con los materiales y el otro se refiere a la posibilidad de utilizar estos recursos en el aula.

Palabras clave: Educación Matemática. Formación continuada de profesores que enseñan Matemáticas. Materiales manipulables. Concepciones.

\section{Introdução}

O uso dos Materiais Manipuláveis (MM) é tema de numerosas pesquisas na área da Educação. Especificamente no campo da Educação Matemática, diversos estudos foram (e são) desenvolvidos, cujos resultados constatam a funcionalidade de tais recursos no ensino de Matemática. Lorenzato (2012), Passos (2012) e Turrioni e Pérez (2012) concordam que os MM podem ser facilitadores da aprendizagem de Matemática. Nesse mesmo sentido, Santos e Gualandi (2016) verificaram que o Laboratório de Ensino de Matemática (LEM) contribui para minimizar as dificuldades enfrentadas pelos alunos em aprender Matemática, uma vez que 0 manuseio dos materiais existentes nesse ambiente, ou mesmo fora dele, Ihes possibilita a abstração dos conteúdos. No entanto, Santos Filho, Oliveira e Cabral (2019) sinalizam que os MM por si só não desempenham o seu papel educativo, sendo necessário a intervenção docente.

Esse cenário acentua a figura do professor durante o processo de aprendizagem via MM, e nos revela a importância de se discutir com os professores sobre as possibilidades e potencialidades dos MM para o ensino de Matemática. Santos e Gualandi (2016) propuseram esse espaço de discussão na formação continuada de professores:

\footnotetext{
Em nossa pesquisa, levantamos dados que merecem uma análise mais detalhada e até mesmo um estudo mais aprofundado, principalmente no que diz respeito ao uso de Materiais Manipuláveis pelos professores em suas salas [...] Muito ainda deve ser feito, inclusive na formação continuada de professores de Matemática, na qual o professor pode ter um maior contato com o LEM e com os Materiais Manipuláveis, aprimorando - dessa forma - sua práxis docente (SANTOS e GUALANDI, 2016, p. 11).
}

Em uma pesquisa intitulada Estudos sobre as concepções de professores que ensinam Matemática: o boletim de Educação Matemática em tela, Matos (2016) evidencia que a busca por compreender as concepções de professores que ensinam Matemática pode mostrar caminhos para melhorar o ensino e a aprendizagem. Ao final desse mesmo estudo, a autora reforça a 
necessidade de conhecer as concepções dos professores, uma vez que eles vivenciam em suas práticas letivas situações complexas que merecem ser compreendidas, a fim de melhorar o ensino e aprendizagem de Matemática.

Sendo assim, a pesquisa que inspirou este artigo teve a intenção de responder a seguinte questão: como uma oficina, como possibilidade de formação continuada, pode contribuir na mudança das concepções dos professores sobre o uso de MM no ensino de Matemática?

Para respondermos à essa questão-problema, apresentamos, inicialmente, o referencial teórico em que baseamos esta pesquisa e, em seguida, a metodologia sobre a qual delineamos este estudo e a descrição do desenvolvimento da oficina. Por fim, discutimos os dados e apresentamos as nossas considerações finais.

O referencial teórico é dividido em três partes, no qual se abordam, num primeiro momento, discussões sobre os MM e as suas potencialidades para o ensino de Matemática. Em sequência, abordamos o papel do professor no processo de utilização desse recurso, bem como a importância da formação continuada para o aperfeiçoamento da sua prática letiva. Por fim, discutimos brevemente sobre as concepções de professores.

\section{Os materiais manipuláveis}

Durante algum tempo, os principais recursos considerados necessários ao ensino e à aprendizagem da Matemática eram o quadro e o giz. No entanto, diversas pesquisas, em âmbito tanto nacional quanto internacional, têm revelado que a manipulação de materiais é importante para uma aprendizagem significativa, conforme enfatizam Ponte e Serrazina (2004).

Serrazina (1996) define Materiais Manipuláveis (MM) como aqueles que apelam vários sentidos e suscitam o envolvimento físico dos alunos. À vista disso, compreendemos que os MM são objetos que os alunos podem manipular, tocar e sentir.

Damas et al. (2010) trazem uma caracterização ainda mais específica acerca dos MM. Para as autoras, os materiais devem ser classificados em estruturados e não estruturados: os estruturados são os que foram concebidos com um fim matemático: os sólidos geométricos, blocos lógicos, geoplano, entre outros; já os não estruturados são aqueles que não foram confeccionados com um fim matemático, mas que podem auxiliar na aprendizagem: papel, palito de picolé, embalagens de papelão, entre outros. 
Ao considerarmos os materiais não estruturados, somos levados a imaginar que existem muitos recursos a favor do ensino. Esses materiais podem ser do mais simples ao mais rebuscado. Nesse sentido, Lorenzato (2012) destaca que lecionar em uma escola na qual não possui o LEM é uma ótima oportunidade para construí-lo em conjunto com os alunos, utilizando sucatas locais, o que implica custos baixíssimos, além de permitir que tanto o aluno quanto o professor conheçam a aplicação do material confeccionado. Esse mesmo autor revela, inclusive, que talvez a melhor potencialidade do MM seja evidenciada durante a sua construção pelos estudantes.

Passos (2012) destaca que qualquer material pode apresentar situações em que 0 estudante reflita, conjecture, formule, entre outros. No entanto, a autora alerta que os conceitos matemáticos não estão nos materiais, para que sejam abstraídos empiricamente, ou seja, os conceitos deverão ser formados pela ação interiorizada do estudante. Em outros termos, a ideia abordada pela autora é que o aluno não aprende Matemática apenas manipulando, pois é necessário que haja uma atividade mental da sua parte, mediada pelo professor.

Assim como Passos (2012), Lorenzato (2012) também destaca esses mesmos aspectos e acrescenta que o material didático (MD) pode ser um excelente catalizador para o estudante construir o seu saber matemático. Para o autor, MD é qualquer instrumento útil ao processo de ensino e de aprendizagem, como um giz, uma calculadora, um livro, um jogo, uma embalagem, entre outros. Por essas razões, entendemos e assumimos que um MD é um MM.

Compreendemos que, na prática com os MM, o estudante se torna um sujeito ativo no processo de aprendizagem, visto que há um envolvimento direto do dele durante o processo de construção dos conceitos matemáticos. Particularmente, no campo da Geometria, Ponte e Serrazina (2000) alertam que, para construir os conceitos geométricos, é essencial que os estudantes tenham uma aprendizagem ativa. Para que isso ocorra, deve haver a manipulação de materiais e a reflexão sobre as atividades desenvolvidas. Moreira (2018) destaca que as crianças revelam interesse em observar os objetos que as rodeiam e em interagir com eles. Durante essas experimentações é que são processadas as noções de formas e espaços, tão importantes para a aprendizagem de geometria.

De acordo com Santos e Gualandi (2016), é necessário que o ensino de Matemática deixe de ser apenas uma prática reprodutora de atividades, repetições, treinos de exercícios e memorização de regras e fórmulas e ela comece a ser trabalhada de forma mais significativa. Cabe aqui destacar a importância da figura do professor nesse processo, uma vez que o seu papel 
não é mais o de transferir conhecimentos, mas ser um mediador entre o conhecimento e o estudante, tal como nos lembram Santos Filho, Oliveira e Cabral (2019). Sendo assim, o professor deve criar condições para que a aprendizagem se torne mais compreensiva, de forma a provocar os estudantes a desenvolver pensamentos mais organizados para, assim, conceber os conceitos matemáticos e suas aplicações.

À vista disso, compreendemos que a formação continuada do professor de Matemática é uma alternativa para oferecer um ambiente de discussão sobre a utilização dos MM no ensino dessa disciplina, funcionando como espaço de reflexão de suas práticas.

\section{0 papel do professor ante o uso dos MM e a formação continuada em Matemática}

Embora os MM sejam alternativas para minimizar as dificuldades dos alunos em aprender Matemática, alguns professores optam por não os utilizar em sala de aula. Lorenzato (2012) assinala que existem preconceitos em relação aos MD, inclusive os de Matemática. Além disso, 0 autor destaca que diversos professores, inseridos no ambiente escolar, não conhecem o LEM, enquanto outros o rejeitam sem ao menos terem experimentado, e alguns o utilizam de maneira inadequada.

É fato que alguns MM despertam no aluno a curiosidade, além de tornarem a aula mais dinâmica e atrativa. No entanto, esses não devem ser somente os motivos pelos quais os professores devem optar por utilizar tal recurso. O objetivo principal a ser almejado é a aprendizagem da Matemática. À vista disso, é necessário que o professor reflita antes mesmo de escolher e utilizar o MD como recurso para as suas aulas (TURRIONI e PEREZ, 2012). Cabe aqui destacarmos a importância do planejamento nesse processo, tão defendido por Santos Filho, Oliveira e Cabral (2019). Para eles, o professor deve planejar a aula com os MM, tendo em vista os objetivos que se pretende alcançar.

Existem diferentes opções de se utilizar os MM na sala de aula. Por isso, Lorenzato (2012) orienta ser importante o professor questionar-se sobre as razões que o levam a utilizá-los. Tais questionamentos são a) para iniciar um conteúdo?; b) para auxiliar na compreensão dos resultados? As respostas a essas perguntas são o que, segundo o autor, facilitarão na escolha de tal recurso. Diante do exposto por Lorenzato (2012), acrescentamos que os questionamentos acerca da utilização dos MM se caracterizam em três vertentes, a saber: a) iniciar um conteúdo; b) auxiliar na exploração e fixação de um conteúdo; c) ser instrumento de avaliação. 
Diante dessas discussões, percebemos que o professor tem um papel importante no processo de construção do conhecimento do estudante via MM. Serrazina (1990), além de enfatizar a importância do papel do professor em optar por MD como recurso para o ensino, observa que o espaço de formação do professor é favorável às reflexões sobre o uso desses recursos e, portanto, deve-se investir na formação tanto inicial quanto na continuada do professor.

De forma a complementar a formação inicial, Perrenoud (2000) considera que os espaços de formação continuada configuram um lugar privilegiado para que o professor reflita sobre qualquer proposta pedagógica que venha a despertar novas posturas ante 0 conhecimento. Aliados a esse pensamento, compreendemos que, se o professor não estudou sobre os MM na sua formação inicial, a formação continuada é, então, o espaço ideal para isso. Se, por outro lado, ele teve o contato com esse recurso na sua formação inicial, por outro, a formação continuada será uma oportunidade para o professor refletir, dialogar, pensar em soluções para o ensino, entre outras contribuições.

Entende-se que a formação continuada é, portanto, uma oportunidade para o professor aprimorar e repensar a sua prática letiva, a qual, segundo Ponte e Serrazina (2004), é um dos elementos que mais contribuem para a qualidade de ensino e da aprendizagem dos alunos.

\section{Concepções de Professores: uma breve discussão}

O conceito de concepção se relaciona com opinião, mas não se limita somente a isso. Segundo o que nos inspira Thompson (1997), a concepção de um professor sobre a Matemática contempla as suas visões, crenças e preferências. Elas são constituídas a partir das experiências individuais e coletivas (PONTE, 1992; MATOS, 2016). Mais que isso, a constituição da concepção de um professor sobre a Matemática pode ser influenciada pela forma como essa disciplina foi-lhe ensinada (MATOS, 2016). Sendo assim, entendemos que a concepção do professor é formada por suas próprias experiências e influenciada pela interação com o meio profissional e social.

De acordo com Ponte (1992), as concepções têm uma natureza essencialmente cognitiva, e isso nos leva pensar as relações entre elas e a prática letiva de um professor. Thompson (1997) afirma que as crenças, visões e preferências de um professor sobre um conteúdo desempenham papel importante no momento de ensiná-lo ao aluno. Matos (2016) corrobora com essa afirmação e acrescenta que as concepções também influenciam na maneira como os professores pensam em seus alunos, planejam suas aulas e pensam o currículo. Nessa mesma direção, Ponte (1992) 
enfatiza que as concepções podem interferir nas práticas, no sentido em que apontam caminhos, decisões, entre outros. Por outro lado, esse autor destaca que novas práticas podem gerar novas concepções.

À vista disso, compreendemos que a concepção de um professor sobre a Matemática pode influenciar em suas práticas letivas. Sendo assim, já no contexto desta pesquisa, entendemos que as concepções docentes sobre os MM podem justificar as suas ações na sala de aula, o que reforça a importância de refletirmos sobre as potencialidades desse recurso didático.

\section{Metodologia da pesquisa}

A referida pesquisa foi realizada com dez professoras que ensinam Matemática na Educação Básica, especificamente do $1^{0}$ ao $9^{a}$ ano do Ensino Fundamental e de Educação Especial, em uma escola pública, situada no município de Marataízes, no sul do estado do Espírito Santo. $O$ principal fator que contribuiu na seleção dessa escola foi a aproximação entre os funcionários em que nela trabalham e a pesquisadora, a qual realizou nessa instituição, durante dois anos, o estágio não obrigatório.

Trata-se de uma pesquisa de abordagem qualitativa que, para Bogdan e Biklen (1994), permite a utilização do ambiente natural como fonte direta de dados e o pesquisador como principal instrumento. Sendo assim, com a intenção de alcançarmos o objetivo traçado para esta pesquisa e respondermos à questão-problema - como uma oficina, como possibilidade de formação continuada, pode contribuir na mudança das concepções dos professores sobre o uso de MM no ensino de Matemática? - , realizamos um estudo de cunho qualitativo e desenvolvemos uma oficina sobre os MM no ensino de Matemática para professores que ensinam essa disciplina, como uma possibilidade de formação continuada.

A fim de alcançarmos o primeiro objetivo específico traçado para esta pesquisa, o qual consiste em conhecer as concepções dos professores que ensinam Matemática com relação ao uso de MM, utilizamos um questionário aberto. Gil (2010) compreende essa técnica como um conjunto de questões a que respondem, por escrito, os participantes da pesquisa. Utilizamos o questionário aberto também com a intenção de alcançarmos o segundo objetivo específico deste trabalho: descrever as concepções dos professores participantes de uma oficina sobre o uso de MM nas aulas de Matemática. 
De acordo com Gil (2010), as técnicas de interrogação ${ }^{1}$ possibilitam a obtenção de dados do ponto de vista dos pesquisados. Por essa razão, entendemos que esse método foi o mais adequado para alcançarmos os dois objetivos específicos para este trabalho, visto que 0 questionário aberto permite que os participantes da pesquisa respondam as questões detalhadamente, expressando as suas ideias, preferências e opiniões, ou seja, as suas concepções. Do mesmo modo, para esse autor, a elaboração do questionário consiste basicamente em traduzir os objetivos específicos da pesquisa em itens bem redigidos. Ainda sobre essa técnica, o autor destaca que é o meio mais rápido de obtenção de informação, além de garantir 0 anonimato.

\subsection{A oficina}

A oficina² foi desenvolvida em 28 de agosto de 2019, em uma escola pública, situada no município de Marataízes, no sul do estado do Espírito Santo, e teve a duração de 2 horas e 40 minutos, aproximadamente, incluindo 15 minutos de intervalo. Participaram dessa oficina dez professoras que ensinam Matemática nessa instituição, atuantes nas turmas do $1^{\circ}$ ao $9^{\circ}$ ano, e professores de Educação Especial.

A oficina ocorreu em uma das salas de aula da instituição. Nesse espaço, havia um quadro branco, pincel, mesas e cadeiras para todos os participantes. Organizamos as mesas em semicírculo, voltadas para o centro da sala, a fim de criarmos um ambiente de bate-papo e troca de experiências entre os participantes da formação.

Para selecionarmos os MM da oficina, entramos em contato com a pedagoga do $1^{\circ}$ ao $5^{\circ}$ e a do $6^{\circ}$ ao $9^{\circ}$ ano, a fim de termos ideia dos materiais que interessariam àquele grupo de professores. Para as professoras dos Anos Iniciais, a pedagoga sugeriu os MM que trabalhassem o conceito de frações, além de componentes lúdicos, ou, nas palavras da profissional, materiais interessantes. Já a pedagoga dos Anos Finais sugeriu MM que abordassem os polinômios, as regras de sinais e algum específico que trabalhasse o conhecimento abstrato nos alunos.

\footnotetext{
${ }^{1}$ Gil (2010) considera o questionário como uma técnica de interrogação.

2 A oficina foi ministrada pela primeira autora e coordenada pelo segundo autor, que é o coordenador do LEM do campus Cachoeiro de Itapemirim do Instituto Federal de Educação, Ciência e Tecnologia do Espírito Santo (IFES).
} 
Os materiais utilizados pertencem ao $\mathrm{LEM}^{3}$ e foram selecionados dias antes de ocorrer a oficina. Durante a escolha dos MM, consideramos as sugestões das pedagogas e, por essa razão, optamos pelos materiais que estão descritos no Quadro 1.

Quadro 1: Materiais Manipuláveis utilizados na oficina

\begin{tabular}{|c|c|}
\hline Material manipulável & Objetivos didáticos \\
\hline Placas de figuras planas em E.V.A. & $\begin{array}{l}\text { Visualizar as ideias de fração, associando } \\
\text { parte e todo, bem como as operações de } \\
\text { adição e subtração envolvendo frações. }\end{array}$ \\
\hline Tabuleiro & $\begin{array}{l}\text { Trabalhar as ideias de quadrado mágico, } \\
\text { sequência e soma com números naturais. }\end{array}$ \\
\hline Jogo do termômetro & $\begin{array}{c}\text { Visualizar a simetria existente na reta } \\
\text { numerada no conjunto } Z \text {. } \\
\text { Trabalhar a ideia de adição e subtração com } \\
\text { números inteiros relativos. }\end{array}$ \\
\hline Kit polinômios & $\begin{array}{l}\text { Visualizar polinômios opostos, bem como } \\
\text { realizar operações de adição, subtração, } \\
\text { multiplicação e divisão de polinômios de } \\
\text { segundo grau. }\end{array}$ \\
\hline Sólidos geométricos planificados & $\begin{array}{c}\text { Visualizar a planificação de sólidos } \\
\text { geométricos; } \\
\text { Estabelecer relações entre vértices, faces e } \\
\text { arestas; } \\
\text { Calcular áreas. }\end{array}$ \\
\hline
\end{tabular}

Fonte: Dados da Pesquisa

Planejamos o desenvolvimento da oficina em duas etapas. Na primeira, convidamos os

\footnotetext{
3 Destacamos que todos os materiais selecionados para esta oficina foram confeccionados pelo professor coordenador do LEM e pelos monitores que são alunos da licenciatura em Matemática no IFES, campus Cachoeiro de Itapemirim.
} 
professores a responderem o primeiro questionário, que teve como objetivo conhecer suas concepções em relação ao uso de MM. Após esse momento, apresentamos professores o material Placa de figuras planas em E.V.A, e discutimos com eles algumas possibilidades de utilizá-los no estudo de fração. Para tal, pedimos que completassem toda a base da figura com as placas de E.V.A. e retirassem uma ou duas placas, com intenção de problematizar a ideia de fração como parte de um todo. Esta proposta foi trabalhada e socializada em grupos.

Em seguida, apresentamos o material Tabuleiro Mágico e pedimos que os sujeitos explorassem algumas situações que relacionassem o uso das peças do tabuleiro com adição de números naturais. Em seguida, convidamos os professores a socializar as ideias que surgiram ao manusearem o MM. Após esta socialização, apresentamos outras propostas que pudessem envolver o trabalho com o MM explorado naquela situação. Neste momento, destacamos a importância de deixar os sujeitos manusearem o MM com o propósito de identificar as potencialidades do material. Desta forma, percebemos que os professores participantes da oficina discutiram entre os pares a aplicabilidade do material de acordo com o nível de suas turmas, 0 que mostra o envolvimento dos sujeitos na oficina. Na sequência, fizemos um intervalo de 15 minutos.

Para iniciarmos a segunda etapa da oficina, apresentamos o Jogo do termômetro, a fim de explorar as ideias de simetria existente na reta numerada no conjunto $Z$, além de discutir alguns conceitos de adição e subtração com números inteiros relativos. Para isso, escrevemos no quadro branco expressões numéricas que contemplassem a adição e subtração de números inteiros, e convidamos os professores a usar o jogo para identificar os resultados e o processo de construção da adição e da subtração nesse mesmo conjunto numérico. Em seguida, apresentamos o Kit Polinômios e discutimos alternativas para usá-lo no ensino de equações do $2^{\circ} \mathrm{grau}$, tanto completas quanto incompletas. Como proposta de atividade, escrevemos no quadro equações do $2^{\circ}$ grau e pedimos para que eles tentassem resolvê-las utilizando o Kit.

Apresentamos em seguida o MM Planificação de Sólidos Geométricos, e solicitamos aos professores que explorassem o material pensando na utilização em suas turmas. Após as reflexões individuais, os professores socializaram as ideias que emergiram para trabalhar com este MM. Desta forma, enfatizaram as potencialidades deste MM para suas respectivas turmas.

Como parte da segunda etapa da oficina, os professores foram convidados a responder 0 segundo questionário, que teve como objetivo descrever suas concepções quanto ao uso de MM 
nas aulas de Matemática. Após esse momento de coleta de dados, encerramos a oficina.

De acordo com Imbernón (2010), o professor assume um conhecimento que lhe permite criar intervenções em sua prática, quando se dispõe em um ambiente de diálogo profissional e interação social, compartilhando problemas, sucessos e fracassos. Mediante esses aspectos, organizamos uma oficina no intuito de promover esse ambiente, para que os professores pudessem dialogar, trocar experiências e refletir sobre as suas práticas.

\subsection{Os questionários da Pesquisa}

A seguir, apresentamos imagens dos questionários utilizados para coletar os dados da pesquisa, a fim de alcançar os dois objetivos traçados para tal e responder à questão problema.

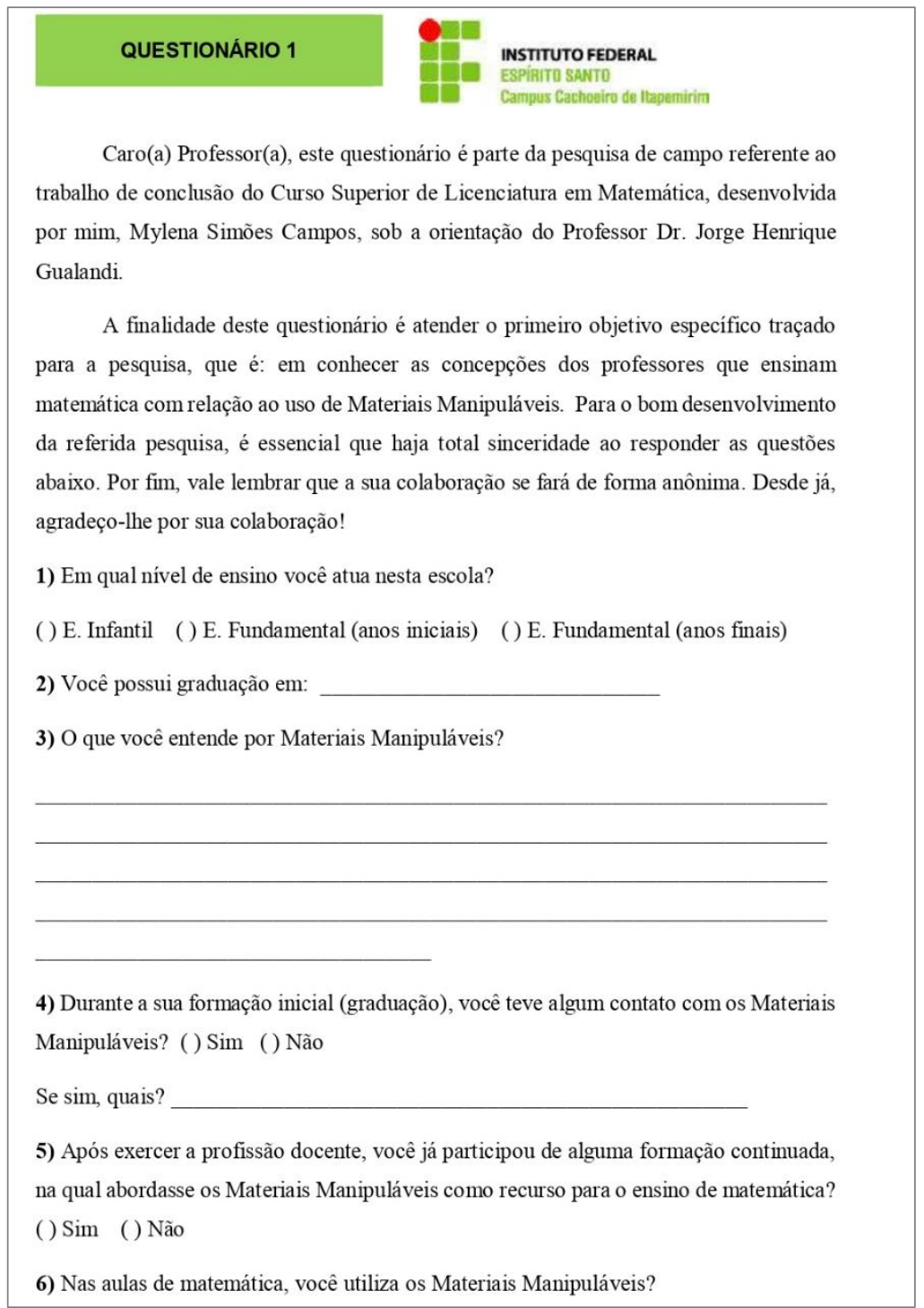

Figura 1: Questionário 1, utilizado na primeira etapa da Oficina (Elaboração dos Autores) 
() Sim ( ) Não

Se sim, em quais conteúdos?

Se não, o que falta para que você use os Materiais Manipuláveis em suas aulas?

7) Como você percebe o uso de Materiais Manipuláveis como recurso para o ensino de matemática?

Figura 2: Continuação do Questionário 1, utilizado na primeira etapa da Oficina (Elaboração dos Autores)

Figura 3: Questionário 2, utilizado na segunda etapa da Oficina (Elaboração dos Autores) 


\section{Análise dos dados da pesquisa}

Para compormos a análise dos dados desta pesquisa, dividimos esta seção em duas subseções para melhor organizar as informações obtidas. Na subseção 6.1, apresentamos os dados referentes ao primeiro questionário, aquele aplicado antes da oficina. Em seguida, na subseção 6.2, discutimos os dados referentes ao segundo questionário, o qual foi aplicado ao final da oficina. A fim de não expormos as professoras participantes da pesquisa, utilizamos nomes fictícios para representá-las.

\subsection{As concepções dos professores sobre os MM antes da oficina}

Como a pesquisa foi realizada com professoras que ensinam Matemática, a qual envolve profissionais que lecionam em diferentes níveis de ensino, julgamos importante identificar essas diferenças. Verificamos que cinco professoras ensinam Matemática nos Anos Iniciais do Ensino Fundamental e as outras cinco, nos Anos Finais.

Apresentamos, na Tabela 1, os dados acerca da formação acadêmica dos envolvidos neste estudo:

Tabela 1: A formação acadêmica das professoras

\begin{tabular}{c|c}
\hline Você possui graduação em: & Quantidade de professoras \\
\hline Matemática & 03 \\
\hline Pedagogia & 07 \\
\hline Educação Especial & 02 \\
\hline Administração & 01 \\
\hline Letras: Português/lnglês & 01 \\
\hline
\end{tabular}

Fonte: Dados da Pesquisa

Com base na Tabela 1, percebemos que duas professoras não identificaram a diferença entre um curso de graduação e de especialização, visto que responderam, no lugar de graduação, o curso de Educação Especial.

De forma a complementar os dados apresentados, destacarmos que duas professoras com licenciatura em Matemática atuam nos Anos Finais do Ensino Fundamental. Além disso, uma professora de Educação Especial possui graduação em mais de uma área: Matemática, 
Administração e Pedagogia. Também atuam na Educação Especial uma professora cuja formação inicial é licenciatura em Letras, e duas que possuem graduação em Pedagogia. Por fim, quatro professoras têm formação inicial em Pedagogia e são atuantes nos Anos Iniciais do Ensino Fundamental. A partir desse cenário, percebemos a formação diversificada das professoras que ensinam Matemática nessa instituição.

Dentre as respostas apresentadas pelos sujeitos, ao serem indagados sobre o que entendiam por MM, destacamos seis respostas, pois entendemos que elas configuram uma síntese das ideias apresentadas pelo grupo de professoras participantes desta pesquisa:

Professora Beatriz: Materiais diversos, comprados prontos ou confeccionados pelo professor e até mesmo pelos alunos.

Professora Carla: Tudo aquilo que facilita o entendimento de determinado conteúdo, ou seja, como introdução ao conteúdo ou fixação.

Professora Diana: Materiais que os alunos podem estar manuseando.

Professora Ester: Recursos auxiliares para fixação de conteúdo.

Professora Fábia: Materiais que os alunos podem ter contato físico.

Professora Giovana: São materiais que os alunos podem manipular ou usar como apoio nas diversas atividades.

Professor Joana: São materiais que podem auxiliar na aprendizagem dos alunos, de forma a facilitar a compreensão do conteúdo. (Questionário 1, 2019)

Com base nas respostas acima, percebemos que a maneira como as professoras Diana, Fábia e Giovana reconheceram os MM se relacionam às ideias de Serrazina (1996), ao enfatizar que os MM são aqueles que os alunos podem manusear. Observamos também que as professoras Carla e Ester identificaram o MM como uma alternativa para fixar os conteúdos, o que é enfatizado por Lorenzato (2012), o qual sugere que o professor se questione sobre os seus objetivos com tais recursos, propiciando-lhe, dessa forma, selecionar os MM que mais se adequam a essa finalidade. Percebemos, ainda, que a professora Beatriz compreende os MM mediante o conceito de materiais estruturados e não estruturados, destacados por Damas et al (2010).

Com o propósito de identificarmos se as professoras tiveram (ou têm) familiaridade com os MM, questionamos a presença de discussões desse recurso nas respectivas trajetórias de formação - inicial e continuada. Apresentamos, na Tabela 2, as respostas à questão.

Ao analisarmos a Tabela 2, observamos que seis professoras não tiveram, em sua formação inicial, discussões acerca dos MM. Isso pode ser explicado pelo fato de as participantes terem formação diversificada ou terem associado os MM somente aos materiais de Matemática. 
Enfatizamos, ainda, que sete dessas professoras tiveram contato com os MM na formação continuada, o que mostra a relevância desse tipo de formação.

Tabela 2: As discussões sobre os MM na formação inicial e continuada das participantes da pesquisa

\begin{tabular}{c|c|c}
\hline $\begin{array}{c}\text { Você teve algum contato com os } \\
\text { MM na sua formação? }\end{array}$ & Formação inicial & Formação continuada \\
\hline Sim & 04 & 07 \\
\hline Não & 06 & 03 \\
\hline
\end{tabular}

Fonte: Dados da Pesquisa

Ao serem indagadas sobre o uso ou não dos MM em suas aulas, identificamos que, dos dez sujeitos, sete incluem os MM em suas práticas letivas.

No questionário 1, permitimos um espaço para as professoras expor os conteúdos que trabalham na sala de aula, quando utilizam os MM. Destacamos algumas respostas:

Professora Ana: em matemática: quantidade, números, sequências, formas geométricas. Em língua portuguesa: formas, palavras, identificar formas, tamanhos.

Professora Diana: identificar números, sinais, operações etc. Em língua portuguesa: identificar letras, sílabas, palavras etc.

Professora Ester: plano cartesiano, regra de sinais, formas de escrita dos racionais.

Professora Inês: na disciplina de língua portuguesa, na alfabetização e na matemática.

Professora Joana: geometria, frações e operações. (Questionário 1, 2019)

Como já apresentado anteriormente, as professoras destacaram suas concepções sobre os MM como um recurso didático. Dentre elas, sete, das dez professoras participantes, responderam que os MM fazem parte das suas práticas letivas. Isso acentua que as concepções influenciam nas práticas dos professores em sala de aula, destacado por Thompson (1997) e Matos (2016).

Há de ressaltarmos que as professoras Ana, Diana e Inês assinalaram que trabalham com MM na disciplina Língua Portuguesa. Com isso, percebemos a relevância em trabalhar com os MM não somente em Matemática, senão em outras áreas.

Às professoras que não usam os MM oferecemos também um espaço para elas pontuarem o que Ihes falta para utilizarem tais recursos. Apresentamos alguns relatos: 
Professora Carla: bom, aqui na cidade M não se tem o laboratório de matemática.

Professora Helena: conhecimento. (Questionário 1, 2019)

Faz-se necessário detalharmos dois casos específicos, observados nos dados da Tabela 2 e nos comentários dessas professoras. Beatriz e Helena relataram não ter estudado sobre os MM durante a sua formação inicial e continuada. Elas enfatizaram, inclusive, que não os utilizam na sala de aula. De forma particular, a professora Helena justificou que the falta conhecimento, para utilizar o MM como recurso didático. Esses dados estão de acordo com o que Lorenzato (2012) destaca em relação às instituições de formação de professores. Para esse autor, são poucas as que ensinam os alunos a utilizar os MM. Como resultado, muitos profissionais não sentem falta desses recursos, ou não percebem as suas potencialidades para o ensino, ou não sabem usá-los.

Além disso, as professoras Beatriz e Carla destacaram que a falta de um espaço adequado é um fator que as impedem de trabalhar com os MM. Como solução para essa dificuldade, Lorenzato (2012) sugere que lecionar em uma escola que não possui o LEM é uma oportunidade para construí-lo, utilizando sucatas locais.

No intuito de conhecermos as concepções das participantes sobre os MM como recurso didático, permitimos um espaço para que elas destacassem as suas opiniões. Ressaltamos algumas falas dessas professoras:

Professor Ana: É importante para o aluno fixar o aprendizado adquirido durante a explicação do conteúdo.

Professor Beatriz: Muito interessante, torna a aula mais dinâmica e compreensível.

Professora Carla: Para introdução do conteúdo, fixação e revisão.

Professora Diana: Um meio prazeroso de introduzir e de fixar um conteúdo.

Professora Ester: São bons aliados na prática docente, mas não o único jeito de ensinar.

Professora Fábia: Com o uso do MM o aluno se interessa mais e o aprendizado é mais aproveitável.

Professora Giovana: É um ótimo recurso para que os alunos possam compreender melhor o raciocínio matemático.

Professora Inês: Uma ferramenta maravilhosa para ajudar no ensino e aprendizado dos alunos (Questionário 1, 2019).

Com base nas opiniões destacadas acima, analisamos que as professoras percebem os MM como um bom recurso didático para o ensino de Matemática. Além de atribuírem características positivas, elas evidenciaram que os MM são ferramentas, recursos, a favor do 
ensino. Especificamente as professoras Ester, Giovana e Inês deixaram essa concepção bem clara, ao utilizar os termos aliados, ferramenta e recurso. Além disso, as professoras Ana, Carla e Diana entendem os MM como um recurso para fixar os conteúdos e, também, Carla e Diana como motivação para introduzir um conteúdo, como destacado por Lorenzato (2012).

É interessante destacarmos que as respostas acima expressaram a opinião, visões e preferências das professoras em relação aos MM como recurso didático, o que vão ao encontro do conceito de concepção, defendido por Thompson (1997).

\subsection{Os reflexos da formação continuada nas possíveis mudanças das concepções dos professores sobre os MM}

Inicialmente entendemos ser importante questionar acerca das discussões desenvolvidas durante a oficina e interrogar se as participantes foram provocadas a utilizar os MM em suas aulas de Matemática. $O$ que nos chamou atenção é que as dez professoras revelaram que se sentiram motivadas a fazer uso dos MM em suas aulas e a forma como a oficina foi conduzida as levou à reflexão de suas práticas, bem como evidenciou a importância do uso dos MM para auxiliar no processo de ensino e aprendizagem.

Questionamos se a oficina ofereceu alternativas para minimizar algum problema de aprendizado na sala de aula. Como resposta a esse questionamento, as dez participantes responderam sim. Além disso, oferecemos um espaço para as professoras pontuarem qual seria esse problema, se houvesse. A seguir, destacamos cinco respostas:

\footnotetext{
Professora Ana: Fração, sequência lógicas, adição, subtração e quantidade.

Professora Diana: Adição, subtração e multiplicação. Fração.

Professora Ester: Composição e decomposição de figuras, operações com frações.

Professora Helena: Normalmente cobramos do aluno o não aprendizado. Precisamos rever nossa prática.

Professora Joana: Subtração e figuras geométricas. (Questionário 2, 2019)
}

A fim de entendermos o sentido de cobrarmos do aluno o não aprendizado, como dito pela professora Helena, questionamos essa participante sobre tal resposta. Para ela, o professor é cobrado pelo não aprendizado dos alunos e, por essa razão, ela destacou ser necessário 0 professor rever (refletir sobre) sua prática profissional, com a intenção de solucionar os problemas de aprendizado de seus alunos. A percepção dessa professora está de acordo com as 
observações de Ponte e Serrazina (2004), os quais percebem que a prática letiva é um dos elementos que mais contribuem para a qualidade do ensino e da aprendizagem.

Ao objetivarmos identificar de que forma a oficina contribuiu na mudança das concepções das professoras sobre o uso de MM como recurso didático, disponibilizamos um espaço para as participantes destacar as contribuições, se houvesse. Enfatizamos algumas falas:

Professora Ana: É de grande valia o aprendizado adquirido com a oficina. Ele vem a melhorar o conhecimento e estimular as estratégias para o aprendizado do aluno, durante a introdução do conteúdo.

Professora Beatriz: Aqui podemos observar que, com materiais fáceis de confeccionar, podemos atingir vários conteúdos que ensinamos em sala de aula, que facilitam 0 entendimento dos alunos.

Professora Carla: Incentivando a buscar materiais de baixo custo para confecção de MM e sempre aguçando a busca de novas experiências.

Professora Diana: Trabalhar de forma lúdica é sempre estimulante para nossos alunos. Eu já trabalhava com MM antes e, agora, estou mais estimulada ainda.

Professora Ester: Conhecer novos jogos e aplicações novas para os que eu já conhecia.

Professora Fábia: $O$ aluno aprende melhor, mobilizando, assim, o seu conhecimento. É uma forma de aprender "brincando".

Professor Helena: Abriu um leque de conhecimento, possibilidades e didáticas. (Questionário 2, 2019)

Verificamos três possíveis mudanças nas concepções das professoras após a oficina. A professora Ana percebia o MM como uma ferramenta para fixar o conteúdo. Após a oficina, ela passou a percebê-lo como uma estratégia para introduzi-lo. Já a professora Beatriz entendia o MM como um componente lúdico, que torna a aula mais dinâmica. Agora, ela o compreende como uma ferramenta para auxiliar na aprendizagem, ao relatar que facilitam o entendimento dos alunos e podem ser confeccionados com materiais fáceis, o que Passos (2012) enfatiza que qualquer material pode apresentar situações em que o estudante aprenda.

Além dessas possíveis mudanças, há de se considerar o caso da professora Helena. No questionário 1, ela relatou que não faz uso de MM na sala de aula e a falta de conhecimento a impede de trabalhar com esse recurso. Já no questionário 2, ela declarou que a oficina abriu um leque de conhecimento. Entendemos, então, que a formação continuada contribuiu agregando conhecimento à essa professora, estimulando-a a utilizar tal recurso em suas aulas. Nesse caso, percebemos uma possível mudança de concepção acerca do MM, bem como uma possível mudança da prática letiva dessa docente. 
No questionário 1, a professora Carla apontou que não utiliza o MM devido à falta de um LEM na escola em que leciona. Encerrada a oficina, essa mesma participante relatou que se sentiu incentivada a confeccionar MM de baixo custo. Por essa razão, percebemos que a professora se sentiu motivada a fazer uso do MM na sala de aula.

Diante disso, observamos que as discussões tecidas no espaço da formação continuada contribuíram na possível mudança da sua prática letiva. Esses dados ilustram as considerações de Perrenoud (2000), que percebe a formação continuada como um lugar privilegiado para que 0 professor reflita sobre qualquer proposta pedagógica que venha a despertar novas posturas ante o conhecimento.

Ao comparar ambos os questionários, compreendemos que a oficina potencializou nas professoras as concepções que já existiam acerca dos MM. No primeiro questionário, a participante Ester apontou que os MM são bons aliados na prática docente; no segundo, ela revelou que a oficina lhe possibilitou conhecer novos jogos e aplicações diferentes para os que já conhecia.

Ao observarmos o relato da professora Diana - Eu já trabalhava com MM antes e, agora, estou mais estimulada ainda —, percebemos que a oficina também potencializou a concepção dessa docente, estimulando-a a utilizar esse recurso.

Percebemos o incentivo também na prática da professora Inês, visto que, no primeiro questionário, ela compreendia o MM como uma ferramenta maravilhosa para ajudar no ensino e na aprendizagem dos alunos. Logo após a oficina, ela nos pediu emprestado o material sólidos geométricos planificados para confeccioná-lo, a fim de utilizá-lo na turma de $2^{\circ}$ ano, em outra escola na qual leciona, localizada em um município vizinho. Após dois meses, retornamos à escola para uma conversa informal sobre a utilização do material com os seus alunos. Nesse diálogo, ao ser indagada sobre tal recurso, ela nos contou que o utilizou em sua sala de aula e essa prática deu resultados positivos, pois os alunos visualizaram melhor a planificação dos sólidos geométricos, bem como tornou a aula mais atrativa.

Cabe aqui destacarmos a importância de compartilhar, em outros espaços, os conhecimentos adquiridos na formação continuada. Nesse caso, por intermédio da professora Inês, uma docente que não participou da oficina, mas que trabalha nessa escola do município vizinho, pôde conhecer esse material e utilizá-lo na sua sala de aula, promovendo, assim, novos espaços para discussões e reflexões acerca da prática letiva desses professores. 


\section{Considerações finais}

Com base nos relatos das professoras acerca dos MM antes e depois da formação continuada, evidenciados nos dois questionários, observamos três possíveis mudanças na maneira como esses sujeitos percebem tais recursos.

A primeira possível mudança foi identificada quando verificamos que uma das participantes não trabalhava com o MM na sala de aula, pois não possuía segurança para isso e, após a oficina, sentiu-se motivada a utilizá-lo e enfatizou que a experiência vivenciada lhe abriu um leque de conhecimento. Vale destacar também que uma das participantes percebia o MM como um instrumento que torna a aula mais atrativa e, agora, compreende-o como um recurso que pode auxiliar na aprendizagem, o que significa que possivelmente ela mudou a sua concepção, ao refletir sobre as potencialidades dos MM para o ensino. Ademais, uma das participantes compreendia o MM como uma alternativa para fixar o conteúdo e agora o identifica como um recurso para introduzi-lo, o que configura uma possível mudança de concepção referente à finalidade para a qual se pode trabalhar com o MM na sala de aula.

Ao considerarmos a questão que orientou esta pesquisa - como uma oficina, como possibilidade de formação continuada, pode contribuir na mudança das concepções dos professores sobre o uso de MM no ensino de Matemática? -, constatamos, com este estudo, que as discussões tecidas nesse espaço de formação permitiram que os professores agregassem conhecimento ao MM e refletissem sobre esse recurso para a aprendizagem de Matemática, contribuindo na possível mudança das concepções sobre o uso do MM como proposta para 0 ensino dessa disciplina.

Uma participante destacou que a oficina lhe possibilitou conhecer aplicações diferentes para os MM que já conhecia. Verificamos, portanto, que a oficina potencializou as concepções que já existiam dessa professora.

O fato de todas as participantes relatarem que se sentiram motivadas a utilizar os MM na sala de aula e, especialmente, uma destacar que ficou incentivada a confeccionar esses recursos, fez-nos verificar que o espaço de formação continuada se configurou um lugar de reflexão sobre as atuações dessas professoras, contribuindo nas possíveis mudanças das suas práticas letivas. Isso ilustra o que Imbernón (2010) propõe como alternativa para a formação continuada, a qual deveria promover a reflexão dos professores, potencializando um processo de autoavaliação sobre o que se faz e por que se faz, ou seja, sobre as suas práticas. 
Percebemos também os reflexos dessa oportunidade de formação continuada na prática letiva de uma participante, visto que esta utilizou, na sala de aula, um dos MM estudados na oficina.

À luz das discussões teóricas abordadas neste artigo, verificamos que os MM são recursos que, aliados às práticas dos professores em sala de aula, podem contribuir no ensino e na aprendizagem de Matemática. Embora muitas pesquisas mostrem as potencialidades desses recursos, ainda há professores que não conhecem o LEM e outros o utilizam de forma inadequada (LORENZATO, 2012). À vista disso, é essencial promover espaços de formação continuada no contexto da utilização de MM, a fim de discutir maneiras de trabalhar com esses recursos na sala de aula.

Em nossa pesquisa, oferecemos esse espaço de discussão, com as professoras, no formato de uma oficina de 2 horas e 40 minutos, e verificamos possíveis mudanças nas suas concepções sobre o uso de MM. É necessária, pois, uma formação continuada com duração de tempo maior para as discussões, centrada na reflexão prático-teórica do professor sobre a própria prática, a fim de verificar se efetivamente houve mudanças nas concepções e como essas mudanças refletem na prática letiva dos professores.

\section{Referências}

BOGDAN, Robert C; BIKLEN, Sari Knopp. Investigação qualitativa em Educação. Tradução de Maria João Alvarez, Sara Bahia dos Santos e Telmo Mourinho Baptista. Porto: Porto Editora, 1994.

DAMAS, Ermelinda; OLIVEIRA, Vânia; NUNES, Raquel; SILVA, Luísa. Alicerces da Matemática: guia prático para professores e educadores. Porto: Areal Editores, 2010.

GIL, Antônio Carlos. Como elaborar projetos de pesquisa. 5. ed. São Paulo: Atlas, 2010.

IMBERNÓN, Francisco. Formação continuada de professores. Tradução de Juliana dos Santos Padilha. Porto Alegre: Artmed, 2010.

LORENZATO, Sérgio. O Laboratório de Ensino de Matemática e os materiais didáticos. In: LORENZATO, Sérgio. (Org.). O Laboratório de Ensino de Matemática na formação de professores. 3. ed. Campinas: Autores Associados, 2012, p. 3-38.

MATOS, Mônica Gonçalves de. Estudo sobre concepções de professores que ensinam Matemática: o boletim de Educação Matemática em tela. In: ENCONTRO NACIONAL DE EDUCAÇÃO MATEMÁTICA, 12, 2016, São Paulo. Anais do XII ENEM: A Educação Matemática na contemporaneidade: desafios e possibilidades. São Paulo: SBEM, 2016, p. 1-12.

MOREIRA, Joana Vianez. Materiais não estruturados na Geometria e Medida em EPE e no $1^{\circ}$ CEB. 2018. 72f. Dissertação (Mestrado em Educação Pré-Escolar e Ensino do $1^{\circ}$ Ciclo do 
Ensino Básico) - Escola Superior de Educação de Paula Frassinetti. Porto.

PASSOS, Cármen Lúcia Brancaglion. Materiais manipuláveis como recurso didático da formação de professores de Matemática. In: LORENZATO, Sérgio. (Org.). O Laboratório de Ensino de Matemática na formação de professores. 3. ed. Campinas: Autores Associados, 2012, p. 77-92.

PERRENOUD, Philippe. Pedagogia diferenciada: das intenções à ação. Tradução de Patricia Chittoni Ramos. Porto Alegre: Artmed, 2000.

PONTE, João Pedro da, SERRAZINA, Maria de Lurdes. Didáctica da Matemática para $01^{\circ} \mathrm{Ciclo}$ do Ensino Básico. Lisboa: Universidade Aberta, 2000.

PONTE, João Pedro da, SERRAZINA, Maria de Lurdes. Práticas profissionais dos professores de Matemática. Quadrante, Lisboa, v. 13, n. 2, p. 51-74, 2004.

PONTE, João Pedro da. Concepções dos professores de Matemática e processos de formação. In: PONTE, João Pedro da. (Org.). Educação Matemática: Temas de Investigação. Lisboa: Instituto de Inovação Educacional, 1992, p. 185-239.

SANTOS FILHO, Jurandi Rodrigues; OLIVEIRA, Lucas Moura de; CABRAL, Macella Ferreira Bonfim. Importância e implantação do Laboratório de Ensino de Matemática. Caderno de Graduação - Ciências Exatas e Tecnológicas, Aracaju, v. 5, n. 2, p. 135-142, mar. 2019.

SANTOS, Rejane Costa dos; GUALANDI, Jorge Henrique. Laboratório de Ensino de Matemática: 0 uso de materiais manipuláveis na formação continuada de professores. In: ENCONTRO NACIONAL DE EDUCAÇÃO MATEMÁTICA, 12, 2016, São Paulo. Anais do XII ENEM: A Educação Matemática na contemporaneidade: desafios e possibilidades. São Paulo: SBEM, 2016, p. 1-12.

SERRAZINA, Lurdes. Didáctica da Matemática: os materiais e o ensino da Matemática. 1996. (22m39s). Disponível em: https://vimeo.com; acesso em 15 fev. 2020, às $16 \mathrm{~h}$.

SERRAZINA, Lurdes. Os materiais e o ensino de matemática. Lisboa: APM, 1990.

THOMPSON, Alba Gonzales. A relação entre concepções de Matemática e de ensino de Matemática de professores na prática pedagógica. Tradução de Gilberto Francisco Alves de Melo e Tadeu Oliver Gonçalves. Zetetiké, Campinas, v. 5, n. 8, p. 11-44, jul./dez. 1997.

TURRIONI, Ana Maria Silveira; PEREZ, Geraldo. Implementando um Laboratório de Educação Matemática para apoio na formação de professores. In: LORENZATO, Sérgio. (Org.). 0 Laboratório de Ensino de Matemática na formação de professores. 3. ed. Campinas: Autores Associados, 2012, p. 57-76. 